\title{
O lugar do sensoriamento remoto no ensino de geografia frente à Base Nacional Comum Curricular - BNCC
}

\author{
Cibele Stefanno Saldanha, Tuane Telles Rodrigues, Mauro Kumpfer Werlang
}

https://doi.org/10.4322/mp.978-65-991393-8-3.c8

\section{Resumo}

O Sensoriamento Remoto quando utilizado na escola permite fornecer subsídios para que os alunos consigam perceber e entender, tanto as dinâmicas físicas quanto as humanas. Também possibilita uma melhor compreensão da Cartografia e isso é muito importante, pois ela se constitui em um dos conteúdos fundamentais no desenvolvimento do pensamento geográfico. Dessa forma, torna-se relevante analisar o papel do Sensoriamento Remoto na Base Nacional Comum Curricular (BNCC) a partir da discussão por meio da comparação entre os PCNs e a BNCC, pontos comuns e divergentes acerca do Sensoriamento Remoto na Geografia Escolar, compreender o papel do Sensoriamento Remoto na BNCC sob uma perspectiva prática e, propor uma atividade para que o Sensoriamento Remoto seja abordado nas aulas, seguindo as possibilidades apresentadas pela BNCC. Usando uma metodologia que envolve caráter investigativo através da revisão bibliográfica e documental relativo a BNCC, buscou-se identificar as questões relacionadas ao papel do Sensoriamento Remoto. Os resultados obtidos mostraram que o Sensoriamento Remoto, como Ciência, não está claramente colocado ao longo do documento. Entretanto, na disciplina de Geografia o documento traz, como ferramenta comum ao Sensoriamento Remoto, as imagens de satélites. A Geografia ao longo do documento da BNCC foi dividida em cinco unidades temáticas, onde a unidade temática na qual contempla as imagens de satélites é denominada "Formas de Representação e Pensamento Espacial" e, objetiva ampliar a concepção da representação gráfica e o raciocínio geográfico, confiando que os educandos consigam elaborar mapas, gráficos, iniciando-se na alfabetização cartográfica.

Palavras-chave: cartografia escolar, ensino em geografia, geotecnologias, parâmetros curriculares nacionais - PCNs.

\section{Introdução}

A revolução científico-tecnológica provocou grandes transformações no mundo moderno nas quais os profissionais da educação precisam atualizar-se por meio de cursos, capacitações e formação continuada, para serem capazes de lidar com as novas tecnologias. Com o advento destas tecnologias, a inclusão digital passou a ser uma preocupação no ensino em sua totalidade, entretanto a Geografia é também responsável pelo aproveitamento destas técnicas na sala de aula, com o uso das geotecnologias.

A geografia carrega consigo a missão de trabalhar com a espacialização de fenômenos físicos e socioeconómicos e as transformações que ocorrem na Terra 
promovidos por esses fenômenos. Neste contexto, o mapa torna-se um instrumento muito utilizado nas aulas. Diante das inúmeras transformações que ocorrem no mundo, dada a rapidez da evolução tecnológica, torna-se imperativa outra postura pedagógica, tanto aos profissionais que produzem o material geográfico, quanto ao material cartográfico e, também aos professores que irão transmitir os conteúdos em sala de aula. Atualmente percebe-se que as reformas relacionadas à educação apontam algumas soluções alternativas no que tange as propostas metodológicas das práticas de ensino. A aquisição do conhecimento passa a ser compreendida como um processo de construção do saber geográfico, sendo o educando um sujeito crítico e atuante na sociedade [1].

A apropriação do homem no espaço geográfico viabilizou a busca contínua pelo desenvolvimento de instrumentos que promovam melhoria e ampliação do monitoramento do meio ambiente. Uma destas técnicas tem se popularizado nas últimas décadas e, vem sendo abundantemente explorada em suas potencialidades, é a geração de imagens provenientes de sensores remotos instalados em satélites artificiais. As imagens permitem uma visão da totalidade e com um detalhamento das extensas áreas da superfície terrestre. Também, o uso dos Sistemas de Informações Geográficas (SIG) na elaboração das atividades em sala de aula, torna as aulas mais interativas, discursivas que prendam a atenção dos educandos, desta forma complementando a utilização do livro didático.

São grandes os desafios que a Geografia vem enfrentando, são questionadas as finalidades de suas práticas pedagógicas, fundamentadas em metodologias de ensino que giram em torno do uso exclusivo de uma apostila ou de um livro didático. As aulas de Geografia são inqueridas pelo predomínio da exposição oral dos conteúdos e subdivididos em unidades temáticas que geralmente são pouco, relacionas com os demais conteúdos. Estas práticas pedagógicas são voltadas ao giz, a lousa e os materiais impressos como as apostilas e os livros didáticos, que ganham destaque, sendo os materiais predominantemente utilizados como recursos didáticos na sala de aula. As aulas são pautadas em conteúdos estipulados e currículos instrumentais, que desconsideram os alunos e os seus desejos, os seus contextos de vida, as suas realidades, os seus sonhos e as suas potencialidades [2].

Portanto o presente estudo justifica-se pela necessidade de investigar a forma que 0 Sensoriamento Remoto vem sendo abordado nos documentos e como a Geografia faz uso dessa ferramenta tecnológica que facilita o ensino e aprendizagem. Como afirma Le Sann [1] apesar da extensa potencialidade das imagens aéreas, a sua utilização no ensino de Geografia são raramente exploradas em sala de aula, esse fato justifica-se pelo pouco conhecimento deste instrumento no ensino. Sendo assim, este estudo irá discutir o papel do Sensoriamento Remoto na Base Nacional Comum Curricular (BNCC), traçando uma comparação entre os Parâmetros Comuns Curriculares, avaliando a forma que os documentos abordam o Sensoriamento Remoto, assim como as imagens de satélites, este estudo é de caráter investigativo e documental.

\subsection{Objetivo geral}

Verificar o papel do sensoriamento remoto na Base Nacional Comum Curricular (BNCC).

\subsubsection{Objetivos específicos:}

1. Compreender o lugar que o sensoriamento remoto ocupa na BNCC sob uma perspectiva prática. 
2. Comparar os PCNs e a BNCC os pontos incomuns e divergentes acerca do sensoriamento remoto na geografia escolar;

3. Propor uma atividade para que o sensoriamento remoto seja abordado nas aulas, seguindo as possibilidades apresentadas pela BNCC.

Cabe destacar a grande e a significativa importância do uso dos mapas, imagens aéreas e outros tipos de representações gráficas no cotidiano escolar para auxiliar na análise, observação, manuseio, reprodução, interpretação e construção do imaginário dos educandos. Destaca-se que a representação gráfica na linguagem geográfica é um procedimento de grande relevância nos estudos da Geografia. Ela desenvolve habilidade de orientação, localização e representação dos educandos em relação aos aspectos da realidade socioespacial [3].

Para Callai et al. [3] a linguagem gráfica desperta o raciocínio lógico possibilitando a análise rápida e detalhada dos conteúdos além de facilitar a memorização das distribuições espaciais, bem como da reflexão e análise das questões ambientais que afetam o espaço vivido. Um destes processos é conhecido como alfabetização cartográfica e visa desenvolver, nos educandos, a construção de estruturas que ofereçam as condições necessárias para o uso cotidiano dos mapas e imagens.

\section{Referencial Teórico}

\subsection{O ensino em Geografia e as diversas linguagens da aprendizagem}

De acordo com Callai et al. [3] a educação geográfica não é simplesmente ensinar e aprender geografia. Vai muito além, significa que o sujeito pode construir as bases de sua inserção no mundo e compreender a dinâmica da paisagem através do entendimento da sua espacialidade. Como consequência dos processos de mundialização e da globalização de todo o conjunto da sociedade existe a necessidade da inserção de novas ferramentas para que seja compreendida. A educação geográfica significativa transpõe a linha de apenas obter informações. Utiliza-se de instrumentos para fazer a análise geográfica para realização de aprendizagens significativas.

A disciplina de geografia tem a missão de preparar o educando para localizar, atuar e compreender o mundo e suas complexidades, problematizar a realidade, reconhecer as dinâmicas existentes no espaço geográfico, pensar e atuar criticamente em sua realidade tendo em vista a sua transformação como cidadão [4].

Cavalcanti [5], afirma que o ensino de geografia tem como propósito, trabalhar o educando juntamente com suas referências e conhecimentos adquiridos na escola e sistematizá-las em contato com a sociedade, com o cotidiano, para assim criar um pensar geográfico que contemple a análise da natureza e a relação com a sociedade.

Segundo Callai et al. [3] as diversas linguagens são utilizadas como instrumentos de aprendizagem para possibilitar a construção do conhecimento ministrado em sala de aula. Isto torna-se possível quando o professor organiza sua aula em busca de uma aprendizagem relacionada ao cotidiano, abordando temáticas nas quais os educandos compreendam não só o mundo como também o lugar em que vivem. O uso dos diferentes recursos didáticos em sala de aula sempre foi uma referência na discussão de propostas inovadoras no ensino. Estas propostas têm se alicerçado em um discurso de reforma educacional, o qual passou a ser sinônimo de renovação pedagógica, progresso e mudança [6]. 
O MEC [7] destaca a importância do uso de diferentes linguagens como novas formas de aprendizagem. Uma das exigências das Políticas Educacionais atuais diz respeito à produção e a distribuição desses inúmeros materiais para que o professor possa utilizá-los durante as suas aulas. Seus usos estão diretamente ligados à didática do docente e ao conhecimento tanto da metodologia de ensino como da própria ciência geográfica.

Castellar e Vilhena [8] enfatizam esta discussão e destacam que, ao utilizar os materiais didáticos, o professor precisa ter domínio do uso que fará e também ser seletivo na organização do material. Um dos recursos de que os professores fazem uso são as diferentes linguagens, na medida em que todos são responsáveis pela capacidade leitora e escritora do aluno.

Segundo Novak [9], a educação deve ter em conta os cinco elementos básicos e que estes interatuam entre si para construir a experiência, que resulta de uma aprendizagem significativa. Essa ideia postula a concepção de educação e de ensino em que o desafio não é apenas passar informações ou aplicar conteúdos de maneira mecânica em situações do cotidiano, mas compreendê-los para que, na aplicação, haja sentido e coerência com a realidade, ou seja, articular as referências teóricas com a prática.

Segundo Castellar e Vanzella [10], quando o professor define seus objetivos, organiza os conteúdos, conceitos e conhece os seus alunos, torna-se mais fácil perceber e criar condições para que ocorra de fato uma aprendizagem significativa. Nesta perspectiva, considera-se que a aula é o momento principal no qual se pode organizar o conhecimento e o pensamento do aluno, a partir de atividades de aprendizagem.

\subsection{A utilização do Sensoriamento Remoto na educação}

De acordo com Paiva et al. [11] apesar do sensoriamento remoto estar se disseminando e, consequentemente se popularizando nas últimas décadas, os avanços na área ainda são considerados insuficientes. Segundo as autoras é na geografia que o sensoriamento remoto se destaca como disciplina. Em muitos cursos o sensoriamento remoto é ofertado como disciplina optativa, e como consequência disso, o número de profissionais qualificados e com domínio dessa técnica acaba ficando ainda escasso.

Segundo Paiva et al. [11], é necessário propor novos artifícios com o objetivo de promover a difusão do uso do sensoriamento remoto. Uma forma de promover a propagação da ciência é a introdução das ferramentas utilizadas nos níveis do ensino fundamental e médio, levando a um universo mais amplo o conhecimento desta tecnologia, ampliando o seu potencial de aplicação.

Como afirma Crispim e Albano [12] as imagens de satélites possuem diversas utilidades e suas aplicabilidades são vastas e indispensáveis para compreender os fenômenos geográficos da superfície terrestre. Destaca que podem ser trabalhadas em variadas escalas espaciais, o que facilita as discussões em sala de aula. Observa que se pode abordar, desde a localização de qualquer município no planeta, observar as características do local e a distribuição vegetal, climática e hidrográfica, além da observação do relevo e ocupação do solo, assim como é possível acompanhar a evolução dos processos que levam à transformação do espaço.

Segundo Florenzano [13], por meio do uso das tecnologias de sensoriamento remoto no processo de ensino e aprendizagem, há a possibilidade da interpretação de imagens de sensores remotos para a compreensão dos educandos acerca dos 
conceitos que norteiam a geografia, como o lugar, localização, interação do homem com o meio, região e as constantes transformações do espaço geográfico além da forma como estes conceitos se articulam. Conforme Mota et al. [14], as imagens de satélites são recursos didáticos que possibilitam a configuração do planeta Terra em diversas escalas, desta forma, propiciando aos educandos as novidades científicotecnológicas que favoreçam a compreensão da realidade em que estão inseridos e, consequentemente, do exercício de sua cidadania.

O sensoriamento remoto pode assumir a finalidade de proporcionar a aproximação entre a realidade espacial e os conteúdos trabalhados em sala de aula. Entretanto, observa-se que se torna cada vez mais necessário o contato do educando com os diferentes locais que compõem o espaço geográfico. Para Mota et al. [14], é de extrema importância que aprendizagem seja significativa e os educandos consigam observar o que se aprende nas aulas de geografia e as aplicabilidades efetivas no meio em que ele está inserido. A geografia não deve ser ensinada como algo distante do cotidiano. Nesse sentido cabe ao professor mostrar aos alunos como aplicar as geografia e suas técnicas.

As novas tecnologias proporcionam a facilidade do uso para fins de informações geográficas. Assim, os professores podem estimular técnicas de visualização com os educandos, de forma simples, como por exemplo, observar os fenômenos presentes desde a sua residência até a escola. Isso pode tornar-se uma maneira de atrair os educandos para maior interesse nas aulas de Geografia e auxiliar na quebra do paradigma de que a geografia é uma disciplina meramente decorativa [15].

O uso das imagens de satélite no ensino da geografia permite identificar e relacionar os elementos naturais e sócio-econômicos presentes na paisagem, tais como as serras, as planícies, os rios, as bacias hidrográficas, as matas, as áreas agricultáveis ou industriais, as cidades, bem como acompanhar resultados da dinâmica do seu uso. Isso pode servir como um importante subsídio à compreensão das relações entre os homens e de suas consequências no uso e ocupação dos espaços e nas interações com a natureza [15].

\subsection{Geotecnologia no ensino de geografia}

O ensino da geografia objetiva ampliar a capacidade dos educandos de observar, conhecer, explicar, comparar e representar as características de um lugar e de diversas paisagens e espaços geográficos. Para Freire e Valente [16], o uso das tecnologias no âmbito pedagógico pretende integrar o docente junto ao aluno visando a compreensão e a interpretação dos fenômenos socioculturais. É preciso ressaltar que as geotecnologias já possuem seu espaço conquistado no processo de ensino e aprendizagem e já vem sendo abordada nos Parâmetros Nacionais Curriculares.

[...] as geotecnologias, são entendidas como sendo as novas tecnologias ligadas às geociências e às outras correlatas. As geotecnologias trazem, no seu bojo, avanços significativos no desenvolvimento de pesquisas, em ações de planejamento, em processos de gestão e em tantos outros aspectos à questão espacial [17].

As geotecnologias são reconhecidas por fazerem parte do geoprocessamento que envolve um conjunto de técnicas na qual são coletadas, processadas, analisadas e colocadas à disposição com referência geográfica. A geotecnologia é o conceito desenvolvido através das tecnologias de informação, esta é utilizada pela geografia, 
cartografia, topografia entre outras ciências que contemplam o estudo geográfico. Desta forma, as geoinformações são aquisições de materiais que farão parte de análise ou processamento que nesta área é chamada de informações georeferenciadas, com dados mais precisos e imagens em tempo real. Segundo Fitz [18], as geotecnologias são variadas, mas algumas são mais utilizadas no ensino de Geografia sendo elas: GIS, GPS e Google Earth.

- GIS - Geographical Information System: é usualmente conhecido por SIG (Sistema de Informação Geográfica), a sigla inglês GIS, são softwares que trabalham com dados do espaço geográfico, tanto de forma numérica quanto gráfica, utilizados para a elaboração de mapas e banco de dados correlacionados que facilitem a interpretação e a visualização dos fenômenos humanos e naturais [18].

- GPS - Global Positioning System: o Sistema de Posicionamento Global (GPS) é uma ferramenta extremamente útil para a localização de pontos georreferenciados na superfície da Terra. Segundo [18], a tecnologia de posicionamento e localização por satélite assegura precisão elevada de latitude e longitude, cujos resultados são obtidos pelo envio de informações de pelo menos três satélites. Também é informada para o usuário a altitude de sua localização, entre outras funções importantes, o que depende do aparelho e de suas funções disponíveis.

- Google Earth: é um programa disponibilizado gratuitamente na Internet pela empresa multinacional da Google, cuja função é mostrar simbolicamente o planeta Terra em forma tridimensional. Também é possível dar um zoom na imagem e visualizar a superfície terrestre por imagens de satélites com uma nitidez e escala considerável. Esse Programa tem incrível capacidade de interface com o usuário e desde que foi criado teve intensa e crescente aceitação nos meios de comunicação [18].

Os Parâmetros Nacionais Curriculares destacam o fato das novas tecnologias encontrarem-se incorporadas aos atuais modos da vida contemporânea que quando defrontamo-nos com menções à sociedade tecnológica quase que imediatamente somos remetidos ao computador, à Internet, aos robôs, satélites e sensores remotos [19]. Neste sentido as geotecnologias devem ser inseridas como um meio que visa desvendar, incrementar, analisar e vivenciar a prática do professor em sala de aula, com o objetivo de fornecer e despertar o interesse do educando pelo conhecimento científico.

Segundo Almeida e Passini [20] o conjunto de ferramentas computacionais que integram as geotecnologias podem ser descritos como Sistemas de Informações Geográficas -SIG, que são softwares que processam dados espaciais possibilitando a análise e gestão do território observado, juntamente com o sensoriamento remoto, que por meio das imagens de satélite proporcionam uma visão de conjunto multitemporal de extensas áreas da superfície terrestre.

\subsection{Cartografia Escolar}

A Cartografia tem um espaço especial na BNCC [7]. Ela ganha espaço à medida que é a forma de expressão gráfica da superfície terrestre e que, com ela, é possível realizar um diálogo acerca do espaço geográfico através de uma linguagem mais acessível e democrática. A Cartografia Escolar é, portanto, a etapa final do processo de aplicação do sensoriamento remoto no ensino de geografia e, por esse motivo, precisa ser 
destacada sempre que se estabelecer a discussão sobre as dinâmicas espaciais na educação básica. Nesse contexto, Almeida e Passini [20] ressaltam que:

[...] nas grades curriculares dos cursos de licenciatura em Geografia inexiste o Sensoriamento Remoto aplicado ao ensino de Geografia. Se existe é como uma disciplina técnica (e não como área da Didática) da formação do geógrafo que irá trabalhar com Sensoriamento Remoto para fins de pesquisa aplicada ou empresarial. Então, como explicar que o professor tenha este conhecimento aplicado ao ensino se ele não existe sistematizado em nenhuma instância.

Essa relação entre sensoriamento remoto e cartografia dentro da comunidade acadêmica é óbvia. Entretanto, no contexto escolar ela assume outras propriedades que exigem noções particulares de interpretação do espaço geográfico e que, assim como no processo de formação acadêmica, são fundamentais no processo de formação do pensamento geográfico. Essa questão é discutida em diversos artigos sobre ensino de Geografia como em [21-23].

A abstração mental é, na transição das imagens de satélite para produtos cartográficos escolares, um dos componentes que se desenvolvem durante a aprendizagem. Quando trabalhamos com a transposição de imagens de satélites de quaisquer fontes, especialmente do Google Earth (por se tratar de uma ferramenta bastante popular e acessível), essa noção de isolar elementos de uma imagem para que a leitura e interpretação desse espaço seja mais eficiente, mostra como a Cartografia Escolar não é por acaso. Assim, cabe destacar as interpretações de Castrogiovanni e Costella [24] a esse respeito, ao enfatizarem que:

alfabetizar cartograficamente não consiste em desmistificar as noções de representação do mundo através de imagens ou mapas, mas, sim construir noções através de propostas concretas - oficinas, que permitam uma interpretação espontânea dos sinais gráficos, os quais representam um mapa e a organização dessas representações de maneira coerente, dentro de uma perspectiva do ponto de vista de cada mapeador.

A colaboração metodológica da cartografia escolar faz perceber que se trata de uma área fundamental para o ensino de geografia. O domínio dos elementos que possibilitam a análise das representações cartográficas em diferentes escalas, como as cartas, mapas e plantas, assim como o desenvolvimento de habilidades como a lateralidade, as referências e a orientação espacial, necessárias para o entendimento da leitura espacial, contribuem para mais do que simplesmente localizar-se no espaço, localizar pessoas, fenômenos e outros lugares. Ela é um instrumento da Geografia que possibilita aos educandos conhecer o espaço real, e espacializar informações aparentemente abstratas, mas que se mostram perfeitamente compreensíveis quando expressas sobre um desenho, podendo trazer qualquer tema de relevância cultural, social, econômica ou ambiental, para a comunidade. Essas informações tornam-se concretas por meio da cartografia [25].

\section{Metodologia}

O presente estudo desenvolveu-se a partir do método dedutivo, pois os pressupostos foram baseados em conhecimentos já existentes, partindo do geral para o particular. $O$ estudo parte do pressuposto que há insuficiência e deficiência no ensino do 
sensoriamento remoto e são necessários avanços na forma de abordá-lo e desenvolver o tema em sala de aula, já que este é um tema rico em aplicabilidades. Desta forma, realizaram-se levantamentos bibliográficos a fim de verificar como os documentos trazem o tema e, as aplicações no ensino da Geografia. A Figura 1 ilustra os procedimentos metodológicos desenvolvidos neste estudo.

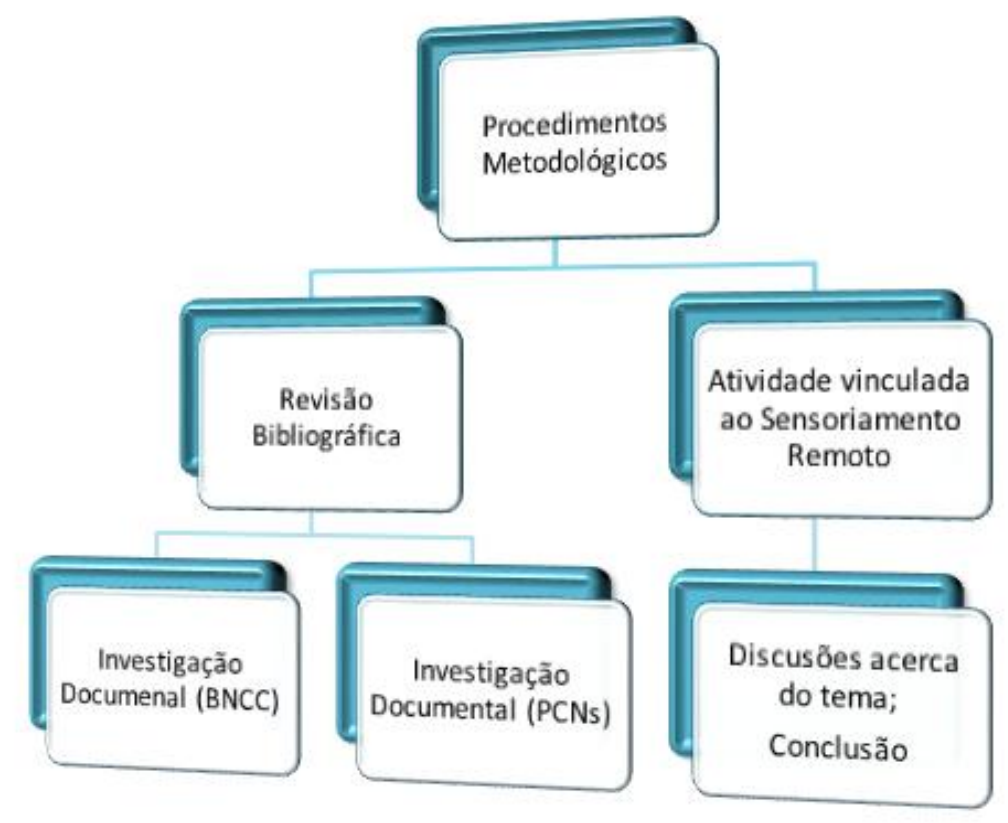

Figura 1. Organograma dos procedimentos realizados na pesquisa.

Inicialmente realizou-se um estudo de carácter investigativo na Base Nacional Comum Curricular com o objetivo de compreender como o Sensoriamento Remoto vem sendo abordado e sua aplicabilidade nas aulas de Geografia, sob a perspectiva prática. Posteriormente, foi realizado o mesmo levantamento nos Parâmetros Curriculares Nacionais - PCNs, elaborando uma comparação entre os dois documentos, traçando uma linha tênue entre eles, observando os pontos incomuns e divergentes referentes ao tema.

Para concluir a pesquisa, propôs-se uma atividade referente ao sensoriamento remoto, onde, primeiramente deve-se escolher uma turma do $5^{\circ}$ Ano em diante, pois é esse 0 período indicado pela Base Nacional Comum Curricular. Selecionar-se-á imagens de satélites provenientes do programa Google Earth das proximidades da escola, com a finalidade de familiarizar os educandos com o espaço vivido. Com isso, espera-se que haja, facilmente, o reconhecimento da paisagem e das transformações no espaço geográfico.

Entende-se que por meio desta atividade é plausível que o professor consiga abordar os conceitos da cartografia escolar como a representação cartográfica, a localização espacial, a paisagem, o lugar e o território.

\section{Resultados}

\subsection{A Base Nacional Comum Curricular (BNCC)}

A Base Nacional Comum Curricular é compreendida como um documento que surgiu com finalidade de atender a demanda do saber, e a fixação dos conteúdos mínimos 
para a educação básica, o que já estava previsto na Constituição Federal do Brasil no que tange o Ensino Fundamental, e posteriormente o ensino médio, de acordo com o Plano Nacional de Educação. Além destes, outros documentos reforçam essa demanda, como a Lei de Diretrizes e Bases da Educação, as Diretrizes Curriculares Nacionais e os Parâmetros Curriculares Nacionais (PCN's) [26].

A elaboração da BNCC estava prevista na Lei de Diretrizes e Bases da Educação (LDB), promulgada em 1996. A Base Nacional Comum Curricular foi estabelecida pelo Plano Nacional de Educação (PNE), votado e sancionado pela presidente Dilma Rousseff, em junho de 2014. Esse documento normativo (a BNCC) deveria ter sido entregue ao Conselho Nacional de Educação (CNE), para sua aprovação final, dois anos depois, ou seja, em junho de 2016. Assim, a BNCC é uma política pública amparada em determinação legal e legítima. Seu objetivo é estabelecer um conjunto de conhecimentos e aprendizagens essenciais a todos os alunos brasileiros, ou seja, todos devem ter acesso ao conteúdo mínimo, ao longo das etapas e modalidades da educação básica, como afirma [26].

\subsection{O sensoriamento remoto na Base Comum Curricular}

Por meio do levantamento investigativo na Base Nacional Comum Curricular foi possível constatar que em nenhum momento o sensoriamento remoto foi citado. Entretanto, as imagens de satélites, a qual é uma das ferramentas mais difundidas dentro do sensoriamento remoto, estão presentes em algumas unidades da BNCC. A Base Nacional Comum Curricular está organizada com base nos principais conceitos da Geografia contemporânea, diferenciados por níveis de complexidade. Neste sentido, é necessário que os educandos dominem os conceitos operacionais e que expressam aspectos diferentes do espaço geográfico como: território, lugar, região, natureza e paisagem. O quadro 1 descreve os princípios do raciocínio geográfico.

Quadro 1. Descrição dos princípios do raciocínio geográfico.

\begin{tabular}{|ll|}
\hline \multicolumn{1}{|c|}{ Princípio } & \multicolumn{1}{c|}{ Descrição } \\
\hline Analogia & $\begin{array}{l}\text { Um fenômeno geográfico sempre é comparável a outros. A } \\
\text { identificação das semelhanças entre fenômenos geográficos é o } \\
\text { início da compreensão da unidade terrestre. }\end{array}$ \\
\hline Conexão & $\begin{array}{l}\text { Um fenômeno geográfico nunca acontece isoladamente, mas } \\
\text { sempre em interação com outros fenômenos próximos ou } \\
\text { distantes. }\end{array}$ \\
\hline Diferenciação & $\begin{array}{l}\text { É a variação dos fenômenos de interesse da geografia pela } \\
\text { superfície terrestre (por exemplo, o clima), resultando na diferença } \\
\text { entre áreas. }\end{array}$ \\
\hline Distribuição & Exprime como os objetos se repartem pelo espaço. \\
\hline Extensão & $\begin{array}{l}\text { Espaço finito e contínuo delimitado pela ocorrência do fenômeno } \\
\text { geográfico. }\end{array}$ \\
\hline Localização & $\begin{array}{l}\text { Posição particular de um objeto na superfície terrestre. A } \\
\text { localização pode ser absoluta (definida por um sistema de } \\
\text { coordenadas geográficas) ou relativa (expressa por meio de } \\
\text { relações espaciais topológicas ou por interações espaciais). }\end{array}$ \\
\hline Ordem & $\begin{array}{l}\text { Ordem ou arranjo espacial é o princípio geográfico de maior } \\
\text { complexidade. Refere-se ao modo de estruturação do espaço de } \\
\text { acordo com as regras da própria sociedade que o produziu. }\end{array}$ \\
\hline
\end{tabular}

Fonte: Adaptado da Base Nacional Comum Curricular - BNCC. 
A Base Nacional Comum Curricular - BNCC contempla o raciocínio geográfico como um meio de exercitar o pensamento espacial. Para isso, deve-se aplicar determinados princípios como mostra o quadro 1, para compreensão dos aspectos fundamentais da realidade como a localização e a distribuição dos fatos e fenômenos na superfície terrestre, o ordenamento territorial, as conexões existentes entre componentes físiconaturais e as ações antrópicas.

Para dar conta desse desafio, o componente geografia da Base Nacional Comum Curricular - BNCC foi dividido em cinco unidades temáticas comuns ao longo do Ensino Fundamental, em uma progressão das habilidades, conforme está ilustrado no quadro 2. Nesta pesquisa enfatiza-se a unidade Formas de representação e pensamento espacial, pois esta contempla o uso das imagens de satélites.

Quadro 2. Unidades temáticas que compreendem a Geografia na BNCC.

\begin{tabular}{|c|c|}
\hline Unidades Temáticas & Objetos de Conhecimento \\
\hline \multirow{2}{*}{ O sujeito e seu lugar no mundo } & Dinâmica Populacional \\
\hline & $\begin{array}{l}\text { Diferenças étnico-raciais e étnico- } \\
\text { culturais e desigualdades sociais }\end{array}$ \\
\hline Conexões e escalas & Território, redes e urbanização \\
\hline Mundo do trabalho & Trabalho e inovação tecnológica \\
\hline $\begin{array}{l}\text { Formas de representação e } \\
\text { pensamento espacial }\end{array}$ & $\begin{array}{l}\text { Mapas e imagens de satélite } \\
\text { Representação das cidades e do espaço } \\
\text { urbano }\end{array}$ \\
\hline $\begin{array}{l}\text { Natureza, ambiente e qualidade de } \\
\text { vida }\end{array}$ & $\begin{array}{l}\text { Qualidade Ambiental } \\
\text { Diferentes tipos de poluição } \\
\text { Gestão pública da qualidade de vida }\end{array}$ \\
\hline
\end{tabular}

Fonte: Adaptado da Base Nacional Comum Curricular - BNCC

A unidade temática formas de representação e pensamento espacial tem como objetivo ampliar gradativamente a concepção e a compreensão do que é um mapa, além de outras formas de representação gráfica. Nesta unidade estão reunidas aprendizagens que envolvem o raciocínio geográfico. Assim, espera-se que, no decorrer do Ensino Fundamental, os alunos tenham domínio da leitura e elaboração de mapas e gráficos, introduzindo a alfabetização cartográfica através das fotografias, mapas, esquemas, desenhos, imagens de satélites, audiovisuais, gráficos, entre outras alternativas, que são frequentemente utilizados no componente curricular.

Desta forma, pode-se compreender que o conteúdo não é completado ao longo da Base Nacional Comum Curricular - BNCC e as imagens de satélites são citadas apenas em dois momentos: vinculados ao conceito de espaço e, a alfabetização cartográfica. A Base Nacional Comum Curricular sugere que os educadores ensinem a unidade Formas de representação e pensamento espacial a partir do $5^{\circ}$ Ano do Ensino Fundamental. 


\subsection{O sensoriamento remoto nos Parâmetros Curriculares Nacionais - PCNS}

Os PCNS foram elaborados com a missão de respeitar as diversidades regionais, políticas e culturais existentes no país, assim, considerando a necessidade de construir referências nacionais comuns ao processo educativo em todas as regiões do Brasil. Os Parâmetros tem o papel de nortear às discussões do projeto político pedagógico, assim como as reflexões sobre a prática pedagógica à análise e seleção de materiais didáticos e de recursos tecnológicos que venham contribuir para formação e atualização profissional. A figura 2 ilustra como os Parâmetros Curriculares estão estruturados no Ensino Fundamental.

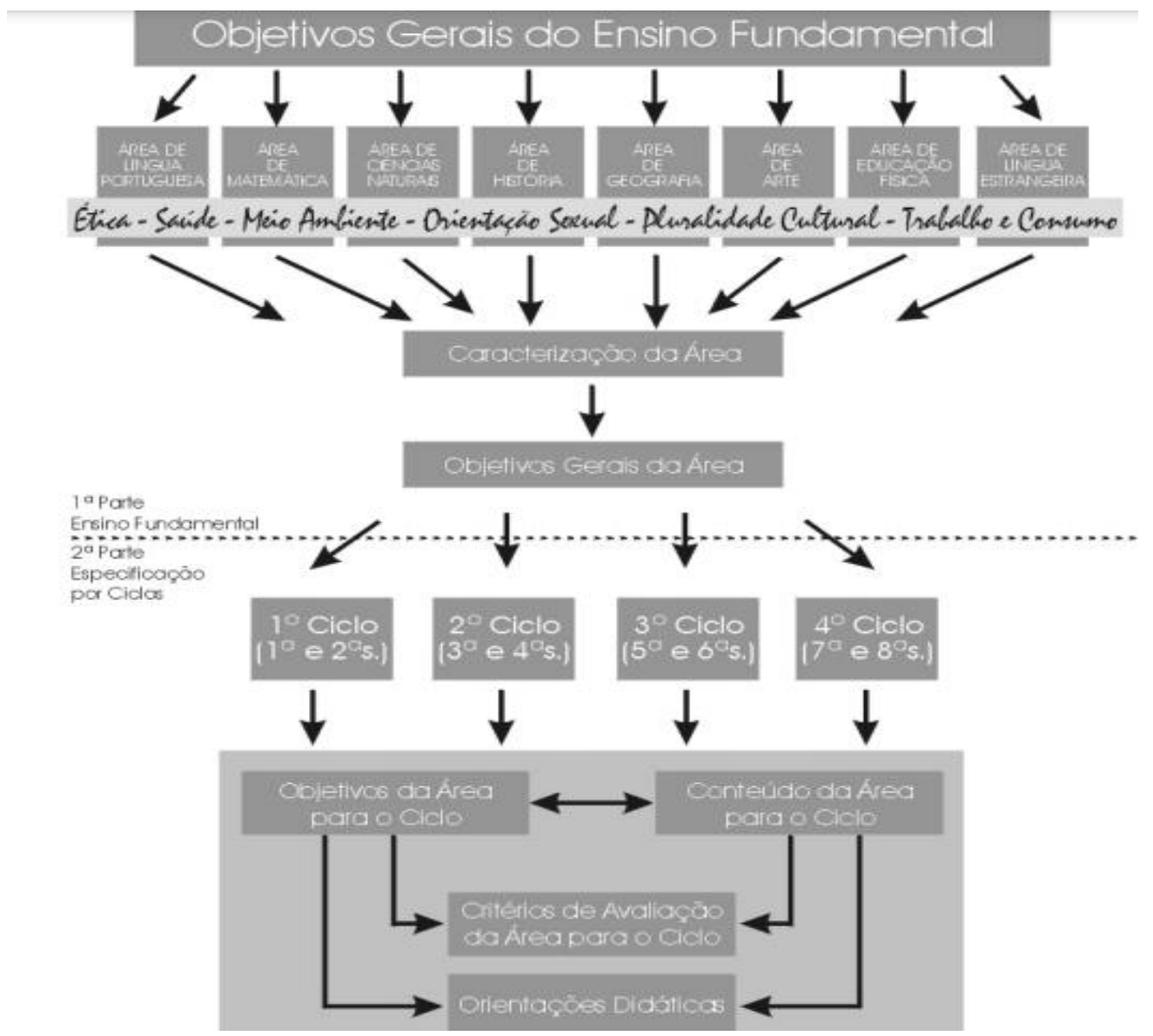

Figura 2. Estrutura dos Parâmetros Curriculares Nacionais para o Ensino Fundamental. Fonte: BRASIL, 1998.

Por meio da ilustração da figura 1, fica nítida a divisão dos parâmetros em 4 ciclos, na qual a Geografia está compreendida no $3^{\circ}$ e $4^{\circ}$ ciclo. $03^{\circ}$ ciclo está divido em quatro eixos. O eixo quatro aborda as imagens de satélites e, assim como na Base Nacional Comum Curricular - BNCC, o conteúdo sensoriamento remoto não está explicito. As imagens de satélites foram citadas em ambos os documento em dois momentos, sendo que nos Parâmetros Curriculares Nacionais estão presentes no $3^{\circ}$ e $4^{\circ}$ ciclo. O quadro 3 ilustra os eixos e as temáticas que encontram-se no $3^{\circ}$ ciclo. 
Quadro 3. Eixos e temáticas que se encontram no $3^{\circ}$ ciclo.

\begin{tabular}{|c|c|}
\hline Eixos & Tema \\
\hline $\begin{array}{l}\text { A Geografia como uma } \\
\text { possibilidade de leitura e } \\
\text { compreensão do mundo }\end{array}$ & $\begin{array}{l}\text { A construção do espaço: os territórios e os lugares } \\
\text { (o tempo da sociedade e o tempo da natureza) }\end{array}$ \\
\hline \multirow{3}{*}{$\begin{array}{l}\text { O estudo da natureza e sua } \\
\text { importância para o homem }\end{array}$} & A conquista do lugar como conquista da cidadania \\
\hline & $\begin{array}{l}\text { Os fenômenos naturais, sua regularidade e } \\
\text { possibilidade de previsão pelo homem }\end{array}$ \\
\hline & A natureza e as questões socioambientais \\
\hline \multirow{4}{*}{$\begin{array}{l}\text { O campo e a cidade como } \\
\text { formações socioespaciais }\end{array}$} & O espaço como acumulação de tempos desiguais \\
\hline & $\begin{array}{l}\text { A modernização capitalista e a redefinição nas } \\
\text { relações entre o campo e a cidade }\end{array}$ \\
\hline & $\begin{array}{l}\text { O papel do Estado e das classes sociais e a } \\
\text { sociedade urbanoindustrial brasileira }\end{array}$ \\
\hline & $\begin{array}{l}\text { A cultura e o consumo: uma nova interação entre o } \\
\text { campo e a cidade }\end{array}$ \\
\hline \multirow{2}{*}{$\begin{array}{l}\text { A cartografia como } \\
\text { instrumento na aproximação } \\
\text { dos lugares e do mundo }\end{array}$} & $\begin{array}{l}\text { Da alfabetização cartográfica à leitura crítica e } \\
\text { mapeamento consciente }\end{array}$ \\
\hline & $\begin{array}{l}\text { Os mapas como possibilidade de compreensão e } \\
\text { estudos comparativos das diferentes paisagens e } \\
\text { lugares }\end{array}$ \\
\hline
\end{tabular}

Fonte: Adaptado dos Parâmetros Nacionais Curriculares.

As imagens de satélites foram mencionadas no eixo onde está referida a cartografia como instrumento na aproximação dos lugares e do mundo, no tema da alfabetização cartográfica à leitura crítica e mapeamento consciente. Segundo Castellar e Vilhena [8] a alfabetização cartográfica deve considerar o interesse que as crianças e jovens têm pelas imagens, atitude fundamental na aprendizagem cartográfica. Os desenhos, as fotos, as maquetes, as plantas, os mapas, as imagens de satélites, as figuras, as tabelas, os jogos, tudo aquilo que representa a linguagem visual continua sendo os materiais e produtos de trabalho que o professor deve utilizar nesta fase.

No $4^{\circ}$ ciclo as imagens de satélites novamente são citadas. Este ciclo é marcado pelo mundo da diversidade da cultura jovem. Os educandos devem aprender a utilizar a tecnologia como ferramenta intermediária da geografia. Na cartografia, podem-se ampliar as possibilidades do trabalho com os seus pressupostos básicos da representação espacial: a localização, a proporção, a distância, a perspectiva, a linguagem gráfica, o trabalho com mapeamento consciente, as cartas analíticas e de síntese. Na leitura cartográfica o professor, desse ciclo, pode lançar mão dos diferentes tipos de mapas temáticos, atlas, globo terrestre, plantas e maquetes mais sofisticadas. Outra possibilidade, que também depende dos recursos, são as formas de registro e interpretação espacial, como o exercício de utilização das fotografias aéreas e imagens de satélites [8].

Desta forma, compreende-se que, assim como na Base Comum Curricular, os Parâmetros Comum Curriculares trazem as imagens de satélites na mesma estrutura e muito semelhantes, pois ambos tratam as imagens atreladas a alfabetização cartográfica. São, portanto, uma ferramenta aliada as primeiras noções espaciais, 
tendo em vista a possibilidade do educador trabalhar os conceitos de lugar, espaço geográfico, território, entre outros.

\subsection{Atividade proposta para ensinar sensoriamento remoto}

Primeiramente o professor de geografia pode selecionar duas ou mais imagens de satélites do bairro onde a escola está localizada, pois é a área que os educandos já conhecem e, com isso, terão facilidade em desenvolver o trabalho. As imagens podem ser obtidas a partir do programa Google Earth e precisam ser selecionadas em um intervalo de pelo menos dez anos, por exemplo, 2010 a 2020.

Após o professor apresentar a atividade, pode sugerir aos educandos a realização de uma análise e interpretação das imagens, anotando as observações e alterações observadas na paisagem ao longo dos anos, indicando quais processos colaboraram para essas mudanças. Também podem anotar quais processos podem contribuir efetivamente para a melhoria do ambiente em que vivem. Ao desenvolver esta atividade os educandos estão sendo instigados a pensar de forma crítica as mudanças que ocorreram ao longo dos anos e, o que pode ser proposto para evitar ou mitigar os danos na paisagem. Desta forma, refletindo sobre a influência humana nas transformações da paisagem, os alunos percebem-se como integrantes, atores e agentes transformadores do espaço geográfico.

Durante o desenvolvimento da atividade, os educandos pode também ser estimulados a refletir sobre tópicos, como por exemplo, a degradação ambiental, as mudanças na paisagem, o desmatamento, a invasão humana em áreas de vegetação e os conflitos de uso, anotando todas as mudanças identificadas por meio das imagens. Esta atividade é simples, de fácil execução e, portanto, torna-se acessível a todos os educadores podendo colaborar de forma eficaz no processo de ensino e aprendizagem.

\section{Conclusão}

Este estudo buscou a compreensão de algumas relações entre a Base Nacional Comum Curricular e os Parâmetros Comuns Curriculares com o viés direcionado ao Sensoriamento Remoto, como forma de averiguar e refletir a importância das geotecnológias no ensino da geografia. Conclui-se que as imagens de satélites tem seu espaço conquistado nos documentos, entretanto a forma de ensinar necessita de avanços, tanto por parte dos educadores quanto dos livros didáticos que, de forma geral, abordam o conteúdo de forma rasa e incipiente embasamento.

Observa-se que é de fundamental importância o professor avaliar o método de ensino adotado. É importante compreender que as novas tecnologias ao serem inseridas nas escolas e nas aulas, são ferramentas aliadas ao professor para tornar as aulas mais interativas, estimulando 0 educando no processo de ensino aprendizagem significativa, pois ao utilizar-se os meios tecnológicos no ensino, aguçam-se a criatividade e a curiosidade.

Constata-se que atualmente existem diversos softwares com os quais os docentes podem trabalhar em sala de aula e, que as técnicas de Sensoriamento Remoto para o ensino, necessitam serem difundidas no intuito de ampliar a ideia do quanto é relevante a colaboração das geotecnologias no ensino da geografia. 


\section{Referências}

[1] Le Sann J.G. Construção de noções básicas de Geografia Física no Ensino Fundamental: Linguagens e novas tecnologias. Geografares (Vitória) 2003; 4(4): 4348. http://dx.doi.org/10.7147/GEO4.1081.

[2] Guimarães I.V. Ensinar e aprender Geografia na Base Nacional Comum Curricular (BNCC). Ensino Em Re-Vista 2018; 25(4): 1036-1055. https://doi.org/10.14393/ERv25n3e2018-11.

[3] Callai H.C., Cavalcanti L.S., Castellar S.V., de Souza V.C. O Ensino de geografia nos trabalhos apresentados no XI Enanpege. Revista da ANPEGE 2016; 12(18): 4355. https://doi.org/10.5418/RA2016.1218.0003.

[4] BRASIL. Objetos de aprendizagem: uma proposta de recurso pedagógico. Brasília: MEC/SEED, 2006. (Coleção Completa)

[5] Cavalcanti L.S. Geografia e práticas de ensino. Goiânia: Editora Alternativa, 2002. vol 1. 127 p. Disponível em: <http://www.apegeo.com.br/encontro2016/wpcontent/uploads/2016/06/ANAIS_IV_EREG_2014.pdf> Acesso em: 26 de nov. 2020.

[6] Fiscarelli R.B de O. Material didático e prática docente. Revista Ibero-Americana de Estudos em Educação 2007; 2(1): 31-39. https://doi.org/10.21723/riaee.v2i1.454.

[7] BRASIL. Parâmetros Curriculares Nacionais. Apresentação de temas transversais e ética. Brasília, Secretaria de Educação Fundame/ntal/MEC, 1997. Disponível em: http://portal.mec.gov.br/seb/arquivos/pdf/livro081.pdf. Acesso em: 28 de nov. 2020.

[8] Castellar S., Vilhena J. Ensino de Geografia. São Paulo: Cengage Learning, 2010. Disponível em:

https://edisciplinas.usp.br/pluginfile.php/2798959/mod_resource/content/1/Texto\%2013 \%20CASTELLAR\%2C\%20S.\%3B\%20VILHENA\%2C\%20J.\%200\%20uso\%20das\%20 diferentes\%20linguagens\%20em\%20sala\%20de\%20aula.pdf. Acesso em: 30 de nov. 2020.

[9] Novak D.J. Conocimiento y aprendizaje: los mapas conceptuales como herramientas facilitadoras para escuelas y empresas. Madrid: Alianza Editoriales, 1998.

[10] Castellar S.M.V. Currículo, educação geográfica e formação docente: desafios e $\begin{array}{lllll}\text { perspectivas. } & \text { Revista } & \text { Tamoios } 2006 ; & \text { 1-10. }\end{array}$ https://doi.org/10.12957/tamoios.2006.611.

[11] Paiva F.V., Maio A.C, Costa S.M.F. A Utilização do Sensoriamento Remoto na Disciplina de Geografia de $5^{\circ}$ A $8^{\circ}$ Séries do Ensino Fundamental da Rede Municipal de Ensino de São José dos Campos. In: Jornada de Educação em Sensoriamento Remoto no Âmbito do Mercosul, v. 4, São Leopoldo, 1-6. Disponívem em: <http://www3.inpe.br/unidades/cep/atividadescep/jornada/programa/t-12_trab_40.pdf>. Acesso em: 3 de dez. 2020.

[12] Crispim L.C., Albano A. O uso das imagens de satélites como recurso didático no ensino de geografia. Revista de Estudos e Pesquisas em Ensino de Geografia 2016; 3(4):46-57. Disponível em:

$<$ https://periodicos.ufsc.br/index.php/pesquisar/article/view/66634/40515>. Acesso em: 5 de dez. 2020. 
[13] Florenzano T.G. Imagens de Satélites Para os Estudos Ambientais. São Paulo: Oficina de 2002.2 Disponível em: $<$ https://edisciplinas.usp.br/pluginfile.php/5692586/mod_resource/content/2/Imagens\% 20de\%20sate\%CC\%81lite\%20para\%20estudos\%20ambientais.pdf>. Acesso em: 7 de dez. 2020.

[14] Mota P.N., Melara E., Cirolini A., Mussoi E.M., Cassol R., Filho. W. P. Noções de Sensoriamento Remoto na Escola de Ensino Fundamental Pinheiro Machado, SANTA MARIA-RS. 4 ${ }^{a}$ Jornada de Educação em Sensoriamento Remoto no Âmbito do Mercosul - Agosto de 2004 - São Leopoldo, RS, Brasil. Disponívem em: <http://www3.inpe.br/unidades/cep/atividadescep/jornada/programa/t-12_trab_50.pdf >. Acesso em: 10 de dez. 2020.

[15] Azevedo J.C. de (Orgs.) Reestruturação Curricular: novos mapas culturais, novas perspectivas educacionais. Porto Alegre: Sulina, 1996. p. 15-33.

[16] Freire F.M.P., Valente J.A. Aprendendo para a vida: os computadores na sala de aula. São Paulo: Cortez, 2001.

[17] BRASIL. Ministério da Educação. Secretaria de Educação Média e Tecnológica. Parâmetros curriculares nacionais. Brasília, 2007. Disponível em: <http://portal.mec.gov.br/setec/arquivos/pdf/BasesLegais.pdf>. Acesso em: $17 \mathrm{de}$ dez. 2020.

[18] Fitz P.R. Novas tecnologias e os caminhos da Ciência Geográfica. Diálogo Tecnologia 2005; 6: 35-48.

[19] Rocha J.A.M.R. GPS: uma abordagem prática. 3. ed. Recife: Editora Bagaço, 2002.

[20] Almeida R.D. de, Passini E.Y. O Espaço Geográfico: Ensino e Representação. 12. ed. São Paulo: Contexto, 1989. Disponível em: $<$ http://observatoriogeograficoamericalatina.org.mx/egal3/Ensenanzadelageografia/Met odologiaparalaensenanza/01.pdf>. Acesso em: 28 de dez. 2020.

[21] Pereira T. O Sensoriamento Remoto como recurso didático no ensino fundamental. Dissertação de mestrado. Uberlândia: Universidade Federal de Uberlândia; 2007.

[22] Ferreira A.L.S., Santos R.L., Barbosa R.S. O Sensoriamneto Remoto e a Cartograia como instrumentos pedagógicos no Ensino de Geografia. InterEspaço Revista de Geografia e Interdisciplinaridade 2015; 1(3): 297-316 https://doi.org/10.18766/2446-6549/interespaco.v1n3p297-316.

[23] Martins G. dos S., Becker E.L.S. Cartografia e sensorimento remoto para o ensino da geografia do lugar- Santa Maria, RS, Brasil. Disciplinarum Scientia 2014; 15(2): 143-160. https://doi.org/10.37780/ch.v15i2.1776.

[24] Castrogiovanni A.C., Costella R.Z. Brincar e cartografar com os diferentes mundos geográficos: a alfabetização espacial. Porto Alegre: EDIPUCRS, 2006.

[25] Rodrigues T.T. O jogo digital como recurso didático na alfabetização cartográfica de aluno surdos e deficientes auditivos em Santa Maria, RS/BR. Dissertação de mestrado. Santa Maria: Universidade Federal de Santa Maria; 2019. 
[26] Cunha L.F.F. da. A geografia escolar e as temáticas físico-naturais na BNCC: desafios à prática docente e à formação de professores. Itinerarius Reflectionis 2018; 14(2): 01. http://dx.doi.org/10.5216/rir.v14i2.51587.

\section{Autores}

Cibele Stefanno Saldanha*, Tuane Telles Rodrigues, Mauro Kumpfer Werlang

Programa de Pós Graduação em Geografia, Universidade Federal de Santa Maria/UFSM, Av. Roraima no 1000, Santa Maria - RS, Brasil.

* Autor para correspondência: cibele2012stefanno@gmail.com 